\title{
Synthesis and biological evaluation of RGD and isoDGR peptidomimetic- $\alpha$-amanitin conjugates for tumor-targeting
}

\author{
Lizeth Bodero ${ }^{\ddagger 1}$, Paula López Rivas ${ }^{\ddagger 2}$, Barbara Korsak ${ }^{3}$, Torsten Hechler ${ }^{3}$, \\ Andreas Pahl ${ }^{3}$, Christoph Müller ${ }^{3}$, Daniela Arosio ${ }^{4}$, Luca Pignataro ${ }^{2}$, Cesare Gennari ${ }^{* 2}$ \\ and Umberto Piarulli ${ }^{* 1}$
}

\section{Full Research Paper}

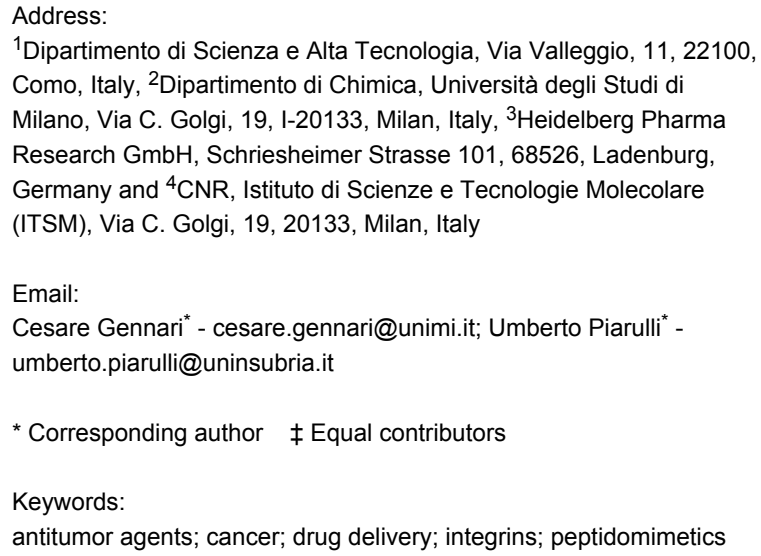

${ }^{1}$ Dipartimento di Scienza e Alta Tecnologia, Via Valleggio, 11, 22100, Como, Italy, ${ }^{2}$ Dipartimento di Chimica, Università degli Studi di Milano, Via C. Golgi, 19, I-20133, Milan, Italy, ${ }^{3}$ Heidelberg Pharma Research $\mathrm{GmbH}$, Schriesheimer Strasse 101, 68526, Ladenburg, Germany and ${ }^{4} \mathrm{CNR}$, Istituto di Scienze e Tecnologie Molecolare (ITSM), Via C. Golgi, 19, 20133, Milan, Italy

Email:

Cesare Gennari* - cesare.gennari@unimi.it; Umberto Piarulli* umberto.piarulli@uninsubria.it

* Corresponding author $\ddagger$ Equal contributors

Keywords:

antitumor agents; cancer; drug delivery; integrins; peptidomimetics

Beilstein J. Org. Chem. 2018, 14, 407-415.

doi:10.3762/bjoc. 14.29

Received: 30 November 2017

Accepted: 31 January 2018

Published: 14 February 2018

This article is part of the Thematic Series "Peptide-drug conjugates".

Guest Editor: N. Sewald

(C) 2018 Bodero et al.; licensee Beilstein-Institut.

License and terms: see end of document.

\begin{abstract}
RGD- $\alpha$-amanitin and isoDGR- $\alpha$-amanitin conjugates were synthesized by joining integrin ligands to $\alpha$-amanitin via various linkers and spacers. The conjugates were evaluated for their ability to inhibit biotinylated vitronectin binding to the purified $\alpha_{V} \beta_{3}$ receptor, retaining good binding affinity, in the same nanomolar range as the free ligands. The antiproliferative activity of the conjugates was evaluated in three cell lines possessing different levels of $\alpha_{V} \beta_{3}$ integrin expression: human glioblastoma U87 ( $\left.\alpha_{V} \beta_{3}+\right)$, human lung carcinoma A549 $\left(\alpha_{V} \beta_{3}-\right)$ and breast adenocarcinoma MDA-MB-468 $\left(\alpha_{V} \beta_{3}-\right)$. In the U87, in the MDA-MB-468, and partly in the A549 cancer cell lines, the cyclo[DKP-isoDGR]- $\alpha$-amanitin conjugates bearing the lysosomally cleavable Val-Ala linker were found to be slightly more potent than $\alpha$-amanitin. Apparently, for all these $\alpha$-amanitin conjugates there is no correlation between the cytotoxicity and the expression of $\alpha_{\mathrm{V}} \beta_{3}$ integrin. To determine whether the increased cytotoxicity of the cyclo[DKP-isoDGR]- $\alpha-$ amanitin conjugates is governed by an integrin-mediated binding and internalization process, competition experiments were carried out in which the conjugates were tested with U87 ( $\left.\alpha_{V} \beta_{3}+, \alpha_{V} \beta_{5^{+}}, \alpha_{V} \beta_{6^{-}}, \alpha_{5} \beta_{1^{+}}\right)$and MDA-MB-468 $\left(\alpha_{V} \beta_{3^{-}}, \alpha_{V} \beta_{5^{+}}, \alpha_{V} \beta_{6^{+}}, \alpha_{5} \beta_{1^{-}}\right)$ cells in the presence of excess cilengitide, with the aim of blocking integrins on the cell surface. Using the MDA-MB-468 cell line, a fivefold increase of the $\mathrm{IC}_{50}$ was observed for the conjugates in the presence of excess cilengitide, which is known to strongly bind not only $\alpha_{V} \beta_{3}$, but also $\alpha_{V} \beta_{5}, \alpha_{V} \beta_{6}$, and $\alpha_{5} \beta_{1}$. These data indicate that in this case the cyclo[DKP-isoDGR]- $\alpha$-amanitin conjugates are possibly internalized by a process mediated by integrins different from $\alpha_{V} \beta_{3}$ (e.g., $\left.\alpha_{V} \beta_{5}\right)$.
\end{abstract}




\section{Introduction}

$\alpha$-Amanitin is a bicyclic octapeptide toxin belonging to the amatoxin family, found in Amanita Phalloides (death cap mushroom), see Figure 1 [1]. Its mechanism of action consists in the inhibition of cellular transcription by an effective blocking of RNA polymerase II, which is present in the nuclei of eukaryotic cells and is responsible for the transcription of DNA to mRNA $[1,2]$. Despite this strong inhibitory activity, $\alpha$-amanitin exhibits only a micromolar cytotoxicity and low cellular uptake in most mammalian cells, due to its strong polarity and poor membrane permeability [2]. One notable exception are human hepatocytes, where the transporting protein OATP1B3 internalizes amatoxins resulting in high liver toxicity $[2,3]$.

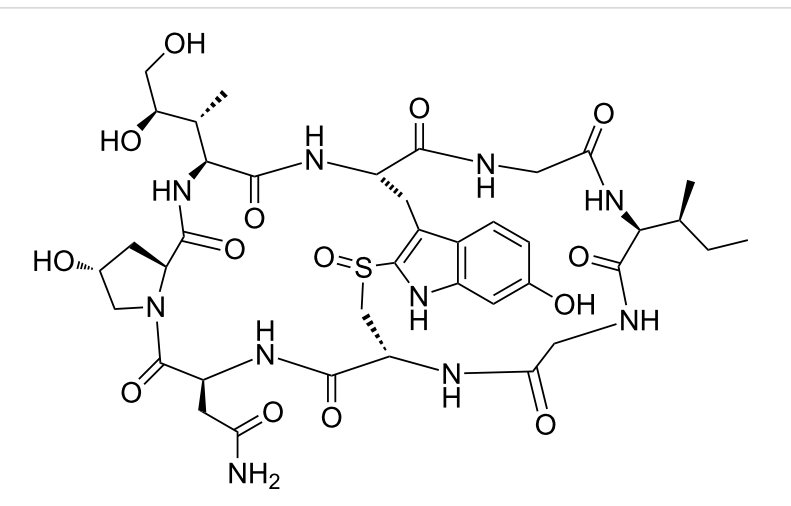

Figure 1: $\alpha-A m a n i t i n$.

This strong toxicity in the presence of endocytosis mediators allowing cell permeation, aroused interest towards the use of $\alpha$-amanitin as a payload for targeted cancer therapy. In 1981, Davis and Preston reported the synthesis of the antibody-drug conjugate (ADC) $\alpha$-amanitin-anti-Thy $1.2 \mathrm{IgG}$, which was 47 -fold more toxic than the unconjugated $\alpha$-amanitin in the murine T lymphoma S49.1 cell line [4]. In 2012, a new ADC containing $\alpha$-amanitin and a chimerized anti-EpCAM (epithelial cell-adhesion molecule) monoclonal antibody was prepared by Moldenhauer and co-workers [5]. The cytotoxicity of this conjugate was tested in EpCAM-overexpressing cancer cell lines obtaining $\mathrm{IC}_{50}$ values from $2.5 \times 10^{-10}$ to $2.0 \times 10^{-12} \mathrm{M}$. Promising results were also observed in mice bearing BxPc-3 pancreatic xenograft tumors, with complete tumor regression in $90 \%$ of the cases after two injections of the $\alpha$-amanitin-antiEpCAM ADC at a dose of $100 \mu \mathrm{g} / \mathrm{kg}$ with respect to $\alpha$-amanitin. In these two examples, the internalization of the monoclonal antibody and subsequent release of the toxin leads to the enhancement of $\alpha$-amanitin activity on the targeted cells.

An alternative approach to the antibody targeted therapy is represented by small molecule-drug conjugates (SMDCs), where the small molecule - usually a peptide or peptidomimetic receptor ligand - avoids the drawbacks of ADCs such as high manufacturing costs, unfavorable pharmacokinetics (low tissue diffusion and low accumulation rate) and possible elicitation of immune response [6]. By conjugation to a specific cell-membrane-receptor ligand, the toxin can be delivered at the tumor site and internalized through receptor-mediated endocytosis. In 2013, Reshetnyak and co-workers conjugated $\alpha$-amanitin to pHLIP ( $\mathrm{pH}$ low insertion peptide) via linkers of different hydrophobicities [7]. The results indicated that pHLIP could deliver $\alpha$-amanitin into cells and induce cell death in $48 \mathrm{~h}$ by a $\mathrm{pH}$-mediated direct translocation across the membrane and cleavage of the disulfide linker in the cytoplasm. In another example, Perrin and co-workers conjugated the $N$-propargylasparagine of an amanitin analog to a cycloRGD integrin ligand (cyclo[RGDfK]) using a copper-catalyzed azide-alkyne cycloaddition [8]. The conjugates were tested in the U87 glioblastoma cell line, but only a slight enhancement in toxicity over $\alpha$-amanitin was observed.

The transmembrane receptor $\alpha_{V} \beta_{3}$ integrin is widely expressed on the blood vessels of several human cancers (for example, breast cancer, glioblastoma, pancreatic tumor, prostate carcinoma) but not on the vasculature of healthy tissues [9-11], and therefore constitutes a suitable therapeutic target in the field of SMDCs. Integrin $\alpha_{V} \beta_{3}$ recognizes endogenous ligands by the tripeptide arginine-glycine-aspartate [12] (RGD) and also by the related sequence isoaspartate-glycine-arginine (isoDGR) [1320]. Many synthetic peptides or peptidomimetics containing these sequences have been prepared and show low nanomolar $\mathrm{IC}_{50}$ values for integrin $\alpha_{\mathrm{V}} \beta_{3}$ binding [21-27]. A number of cyclic RGD and isoDGR ligands containing a bifunctional diketopiperazine (DKP) scaffold have been developed by the Gennari and Piarulli groups in the last decade [24-27]. Among them, the cyclo[DKP-RGD] 1 [25] and cyclo[DKP-isoDGR] 3 [26] (Figure 2) showed a binding affinity for the purified receptor $\alpha_{V} \beta_{3}$ in the low nanomolar range and a good selectivity for this integrin in comparison with integrin $\alpha_{V} \beta_{5}$ (33-34 times, see Table 1).

Furthermore, these ligands were shown to inhibit the FAK (focal adhesion kinase) and Akt (protein kinase B) signaling cascade and the tumor cell infiltration process, performing as true integrin antagonists [27].

Ligands $\mathbf{1}$ and $\mathbf{3}$ were also functionalized with an aminomethyl group $\left(-\mathrm{CH}_{2} \mathrm{NH}_{2}\right)$ as a handle for conjugation to cytotoxic drugs (Figure 2, ligands 2 and 4) [28-30]. Conjugates of the functionalized ligands $\mathbf{2}$ and $\mathbf{4}$ with paclitaxel (PTX) via a 2'-carbamate with a self-immolative spacer and the lysosomally cleavable Val-Ala linker [31] were synthesized (Figure 2, cyclo[DKP- 
<smiles>[R]c1ccc(CN2C(=O)[C@@H]3NC(=O)[C@@H](CC(=O)N[C@@H](CCCNC(=N)N)C(=O)NCC(=O)[C@H](CC(=O)O)NC(=O)CNC(=N)N)N3C2=O)cc1</smiles>

1: $\mathrm{R}=\mathrm{H}(\mathrm{cyclo}[\mathrm{DKP}-\mathrm{RGD}])$

2: $\mathrm{R}=\mathrm{CH}_{2} \mathrm{NH}_{2}\left(\mathrm{H}_{2} \mathrm{NCH}_{2}\right.$-cyclo[DKP-RGD])

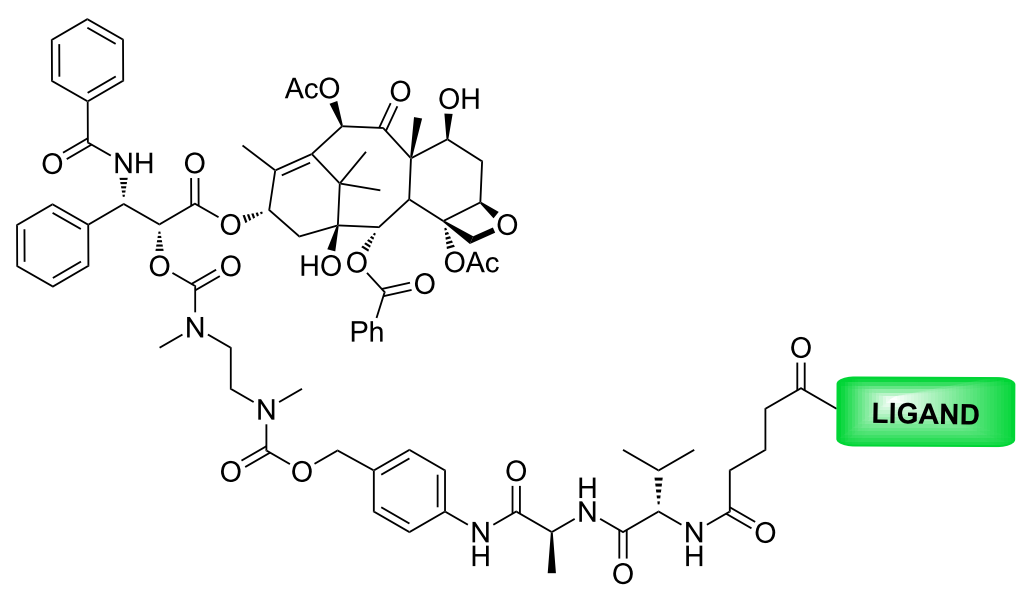

5: ligand $=\mathrm{NHCH}_{2}$-cyclo[DKP-RGD]

6: ligand $=\mathrm{NHCH}_{2}$-cyclo[DKP-isoDGR]

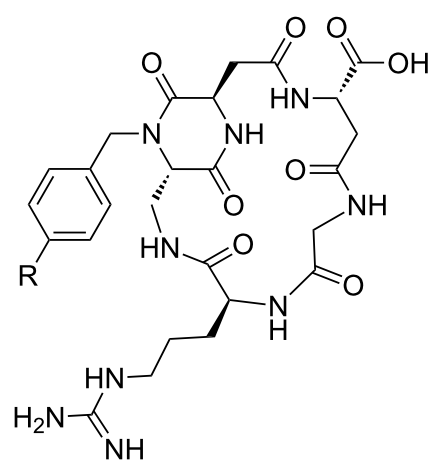

3: $\mathrm{R}=\mathrm{H}$ (cyclo[DKP-isoDGR])

4: $\mathrm{R}=\mathrm{CH}_{2} \mathrm{NH}_{2}\left(\mathrm{H}_{2} \mathrm{NCH}_{2}\right.$-cyclo[DKP-isoDGR])

Figure 2: Structure of the ligands cyclo[DKP-RGD] (1), $\mathrm{NH}_{2} \mathrm{CH}_{2}$-cyclo[DKP-RGD] (2), cyclo[DKP-isoDGR] (3), $\mathrm{NH}_{2} \mathrm{CH}_{2}$-cyclo[DKP-isoDGR] (4) and the related SMDCs cyclo[DKP-RGD]-Val-Ala-PTX (5) and cyclo[DKP-isoDGR]-Val-Ala-PTX (6).

Table 1: Inhibition of biotinylated vitronectin binding to $\alpha_{v} \beta_{3}$ and $\alpha_{v} \beta_{5}$ receptors

\begin{tabular}{cccc} 
ligand & structure (name) & $\mathrm{IC}_{50}(\mathrm{nM})^{\mathrm{a}} \mathrm{\alpha}_{\mathrm{V}} \beta_{3}$ & $\mathrm{IC}_{50}(\mathrm{nM})^{\mathrm{a}} \mathrm{\alpha}_{\mathrm{V} \beta_{5}}$ \\
\hline $\mathbf{1}$ & cyclo[DKP-RGD] & $4.5 \pm 1.1$ & $149 \pm 25$ \\
$\mathbf{3}$ & cyclo[DKP-isoDGR] & $9.2 \pm 1.1$ & $312 \pm 21$ \\
\hline
\end{tabular}

${ }^{\text {a }} \mathrm{C}_{50}$ values were calculated as the concentration of compound required for $50 \%$ inhibition of biotinylated vitronectin binding as estimated by GraphPad Prism software. All values are the arithmetic mean \pm the standard deviation (SD) of triplicate determinations.

RGD]-Val-Ala-PTX 5 and cyclo[DKP-isoDGR]-Val-Ala-PTX

6). Their tumor targeting ability was assessed in vitro in antiproliferative assays comparing an $\alpha_{\mathrm{V}} \beta_{3}$ positive with an $\alpha_{\mathrm{V}} \beta_{3}$ negative cell line [29,30]. The cyclo[DKP-isoDGR]-Val-AlaPTX conjugate 6 displayed a remarkable targeting index $(\mathrm{TI}=9.9)$, especially when compared to the strictly related cyclo[DKP-RGD]-Val-Ala-PTX conjugate $5(\mathrm{TI}=2.4)$ [30].

\section{Results and Discussion}

In the present paper, we report the synthesis and biological evaluation of two cyclo[DKP-RGD]- $\alpha$-amanitin and three cyclo[DKP-isoDGR]- $\alpha$-amanitin conjugates. In these conjugates, the integrin ligands are bound to $\alpha$-amanitin via a 6 '-ether with two different linkers: an "uncleavable" six carbon aliphatic chain (Figure 3, compounds 7 and 8) and a lysosomally 


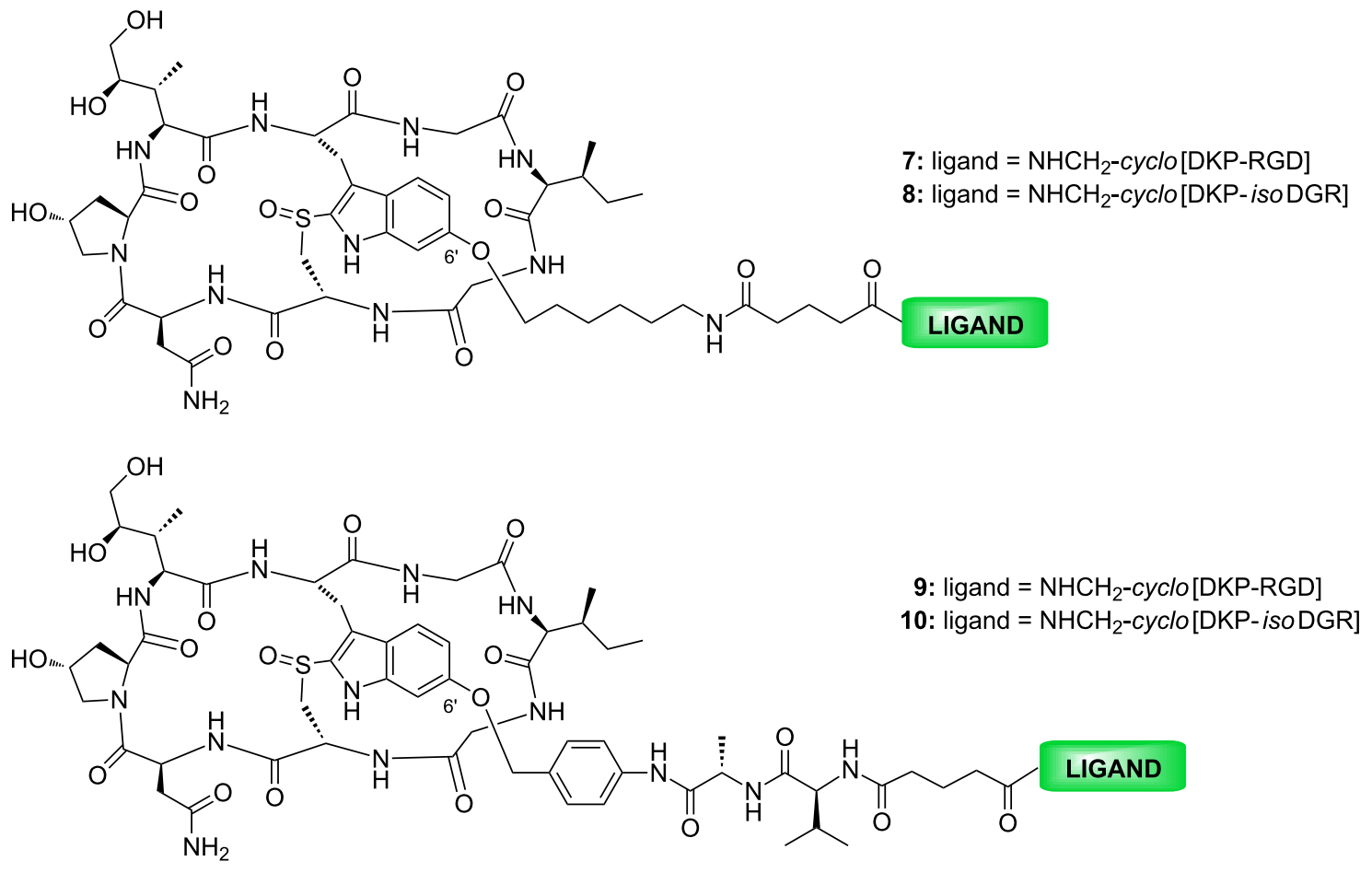

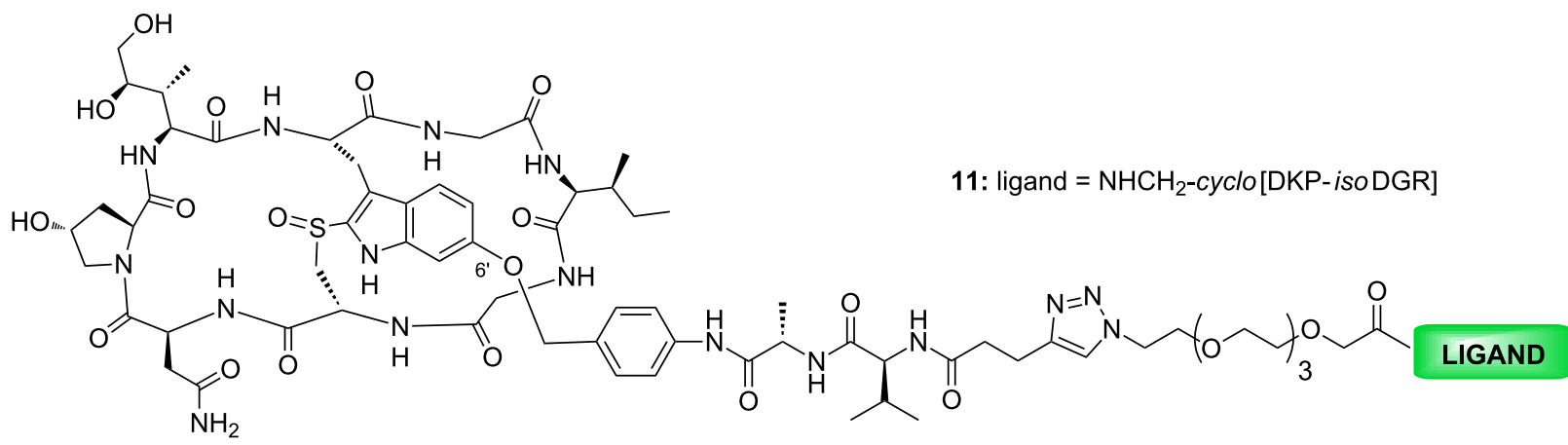

Figure 3: Structure of the $\alpha$-amanitin conjugates: cyclo[DKP-RGD]-uncleavable- $\alpha$-amanitin (7), cyclo[DKP-isoDGR]-uncleavable- $\alpha$-amanitin (8), cyclo[DKP-RGD]-Val-Ala-a-amanitin (9), cyclo[DKP-isoDGR]-Val-Ala- $\alpha$-amanitin (10) and cyclo[DKP-isoDGR]-PEG-4-Val-Ala-a-amanitin (11).

cleavable Val-Ala linker bound to a self-immolative spacer (Figure 3, compounds 9, 10 and 11). Integrin receptor competitive binding assays and cell proliferation assays with an $\alpha_{V} \beta_{3}$ positive (U87) and two $\alpha_{V} \beta_{3}$ negative cell lines (A549 and MDA-MB-468) were performed for all the conjugates.

\section{Synthesis}

Cyclo[DKP-RGD]- $\alpha$-amanitin and cyclo[DKP-isoDGR]- $\alpha$-amanitin conjugates 7-11 were synthesized as described in Scheme 1 and Scheme 2, by joining the functionalized ligands $\mathrm{H}_{2} \mathrm{NCH}_{2}$-cyclo[DKP-RGD] (2) [18,29] and $\mathrm{H}_{2} \mathrm{NCH}_{2}$ cyclo[DKP-isoDGR] (4) [30] to $\alpha$-amanitin via a 6'-ether with various linkers and spacers. Details are reported in Supporting Information File 1.

\section{Integrin receptor competitive binding assays}

Conjugates 7-11 were evaluated for their ability to inhibit biotinylated vitronectin binding to the purified $\alpha_{V} \beta_{3}$ receptor. The calculated half-maximal inhibitory concentrations $\left(\mathrm{IC}_{50}\right)$ are listed in Table 2. Screening assays were performed by incubating the immobilized integrin receptor with solutions of the cyclo[DKP-RGD]- $\alpha$-amanitin and cyclo[DKP-isoDGR]- $\alpha$-amanitin conjugates $\mathbf{7 - 1 1}$ at different concentrations $\left(10^{-12}\right.$ to $\left.10^{-5} \mathrm{M}\right)$ in the presence of biotinylated vitronectin $\left(1 \mu \mathrm{g} \mathrm{mL}^{-1}\right)$ and measuring bound vitronectin.

It was found that the cyclo[DKP-RGD]- $\alpha$-amanitin conjugates 7 and 9 and cyclo[DKP-isoDGR]- $\alpha$-amanitin conjugates $\mathbf{8 , 1 0}$ and 11 retain good binding affinity for $\alpha_{V} \beta_{3}$ integrin, in the same 


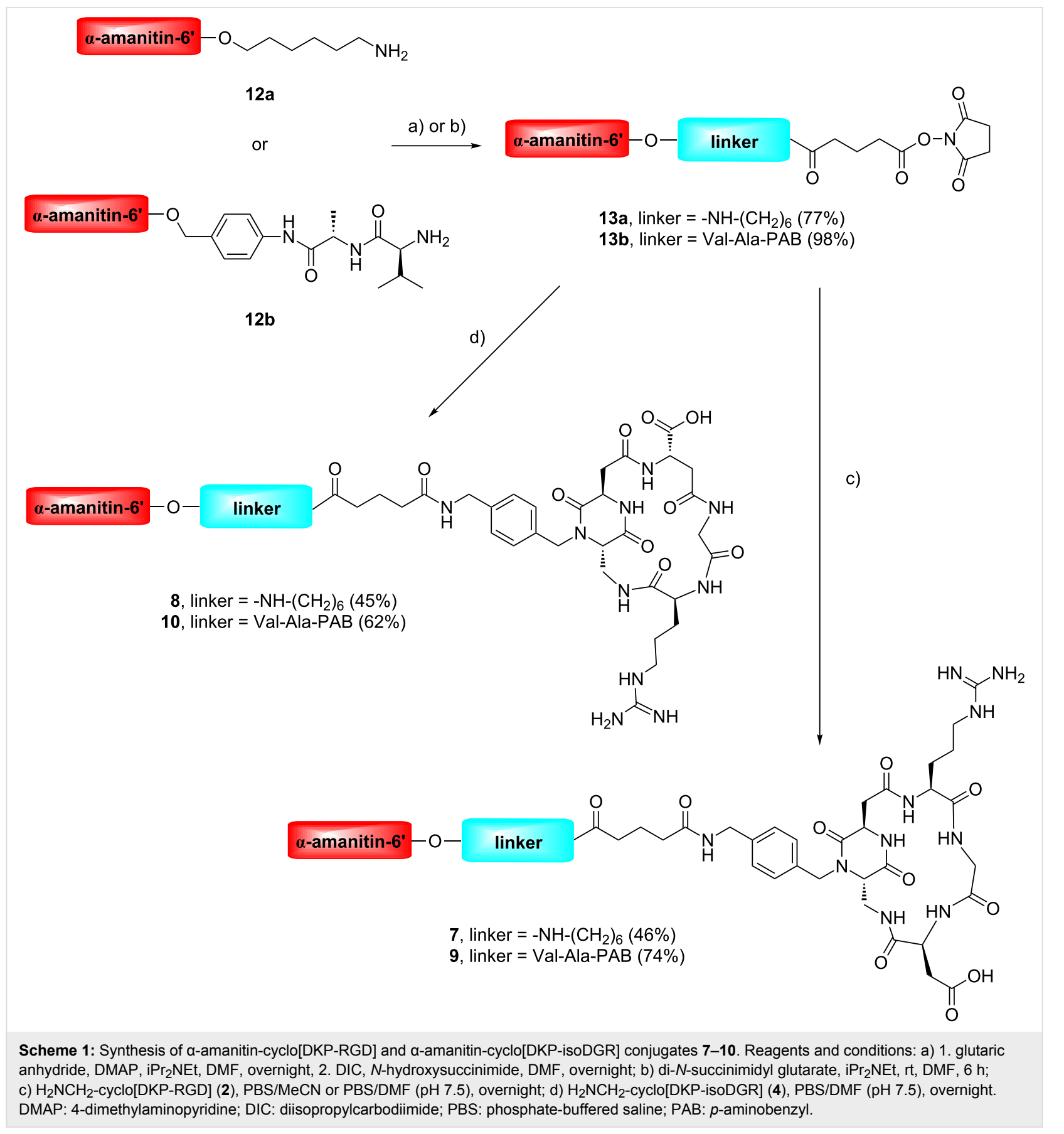

range as the free ligands (cf. Table 2 with Table 1). These results encouraged us to proceed with cell viability assays in $\alpha_{V} \beta_{3}$ positive and $\alpha_{V} \beta_{3}$ negative cell lines, to study the ability of the conjugates to selectively target $\alpha_{V} \beta_{3}$ expressing tumor cells.

\section{Cell viability assays}

The antiproliferative activity of the conjugates was evaluated in three cell lines expressing different levels of $\alpha_{V} \beta_{3}$ integrin. U87 cells (human glioblastoma) were selected as $\alpha_{V} \beta_{3}$ positive, while A549 cells (human lung carcinoma) and MDA-MB-468 (breast adenocarcinoma) [32] were used as $\alpha_{V} \beta_{3}$ negative. The expression of $\alpha_{V} \beta_{3}$ integrin on the cell membrane was assessed by flow cytometry (see Supporting Information File 1, Figure S1), and the results were in good agreement with the literature for U87 and A549 [33-35]. In the case of MDA-MB468 , while the presence of the $\beta_{3}$ integrin subunit is still quite controversial in the literature [36-38], our FACS analysis could not detect any $\alpha_{V} \beta_{3}$ expression (see Supporting Information File 1). 


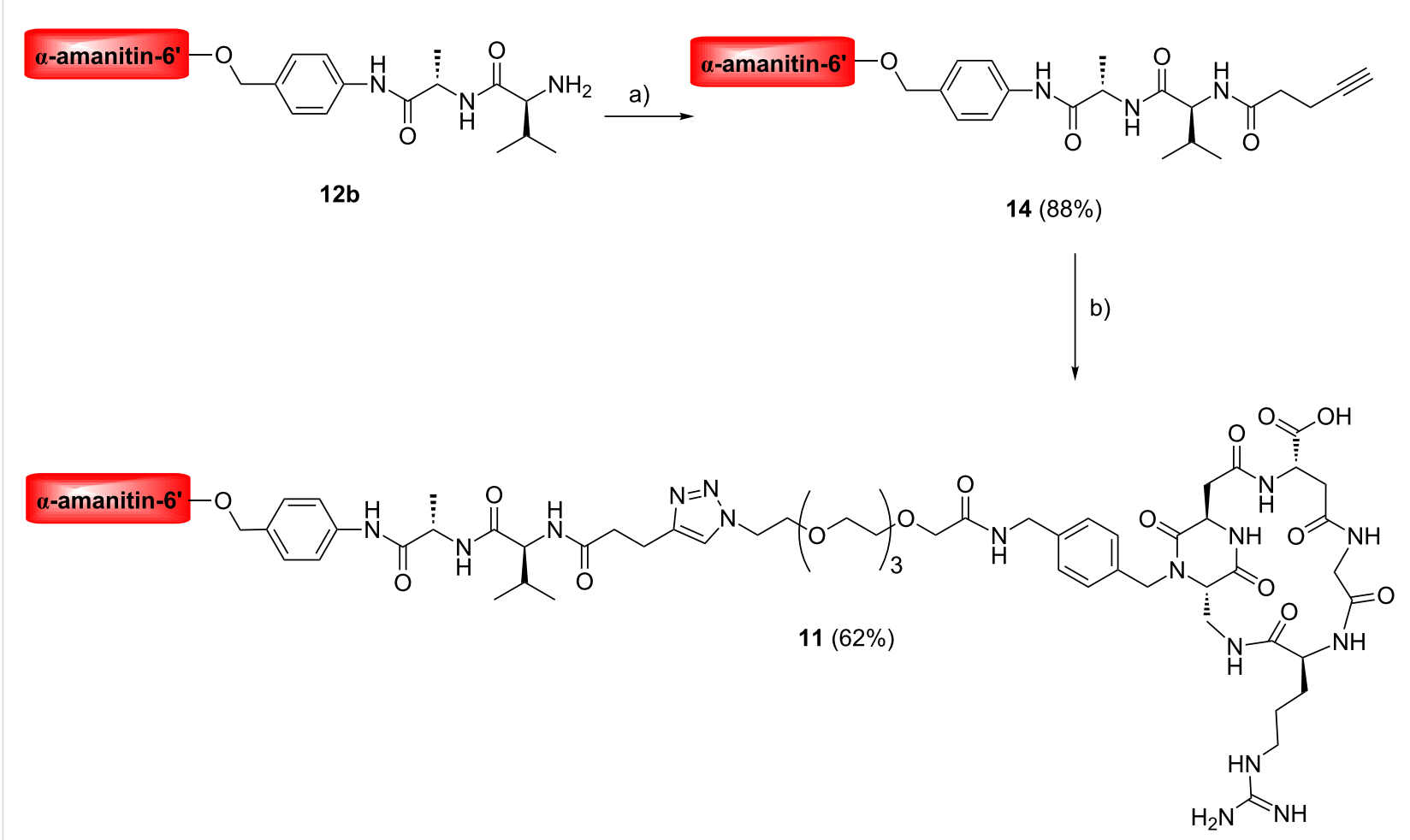

Scheme 2: Synthesis of cyclo[DKP-isoDGR]-PEG-4-Val-Ala- $\alpha$-amanitin conjugate 11. Reagents and conditions: a) 4-pentynoic acid N-hydroxysuccinimidyl ester, i $\mathrm{Pr}_{2} \mathrm{NEt}$, DMF, overnight; b) $\mathrm{N}_{3}$-PEG-4-cyclo[DKP-isoDGR], sodium ascorbate, $\mathrm{CuSO}_{4} \cdot 5 \mathrm{H}_{2} \mathrm{O}$, DMF/water, rt, overnight.

Table 2: Inhibition of biotinylated vitronectin binding to $\alpha_{\mathrm{v}} \beta_{3}$ receptor.

\begin{tabular}{|c|c|c|}
\hline compound & structure (name) & $\mathrm{IC}_{50}(\mathrm{nM})^{\mathrm{a}} \alpha_{\mathrm{V}} \beta_{3}$ \\
\hline 7 & cyclo[DKP-RGD]-uncleavable-a-amanitin & $11.6 \pm 2.4$ \\
\hline 8 & cyclo[DKP-isoDGR]-uncleavable- $\alpha$-amanitin & $6.8 \pm 4.3$ \\
\hline 9 & cyclo[DKP-RGD]-Val-Ala-a-amanitin & $14.7 \pm 6.6$ \\
\hline 10 & cyclo[DKP-isoDGR]-Val-Ala- $\alpha$-amanitin & $6.4 \pm 1.9$ \\
\hline 11 & cyclo[DKP-isoDGR]-PEG-4-Val-Ala- $\alpha$-amanitin & $3.8 \pm 0.3$ \\
\hline
\end{tabular}

${ }^{a} C_{50}$ values were calculated as the concentration of compound required for $50 \%$ inhibition of biotinylated vitronectin binding as estimated by GraphPad Prism software. All values are the arithmetic mean \pm the standard deviation (SD) of triplicate determinations.

The cell lines were treated with different concentrations of the free drug $\alpha$-amanitin and conjugates $\mathbf{7 - 1 1}$ for 96 hours. The cell viability was evaluated with the CellTiterGlo 2.0 assay and the calculated $\mathrm{IC}_{50}$ are shown in Table 3.

The cyclo[DKP-isoDGR]- $\alpha$-amanitin conjugate bearing the lysosomally cleavable Val-Ala linker $\mathbf{1 0}$ proved slightly more potent than $\alpha$-amanitin in the U87 $\left(\alpha_{V} \beta_{3}+\right)$ cell line, as well as in the A549 and MDA-MB-468 $\left(\alpha_{V} \beta_{3}-\right)$ cell lines (2.4-3.1 times, cf. entry 1 with entry 5 in Table 3$)$. The cyclo[DKP-isoDGR]- $\alpha$-amanitin conjugate bearing the lysosomally cleavable Val-Ala linker and a PEG-4 spacer 11 proved slightly more potent than $\alpha$-amanitin in both the U87 $\left(\alpha_{V} \beta_{3}{ }^{+}\right)$ and MDA-MB-468 $\left(\alpha_{\mathrm{V}} \beta_{3^{-}}\right)$cell lines (2.1-2.8 times, cf. entry 1 with entry 6 in Table 3$)$, while in A549 cell line $\left(\alpha_{V} \beta_{3}{ }^{-}\right)$it turned out to be less potent (1.4 times) than the free drug. Cyclo[DKP-RGD]-uncleavable- $\alpha$-amanitin (7), cyclo[DKPisoDGR]-uncleavable- $\alpha$-amanitin (8) and cyclo[DKP-RGD]Val-Ala- $\alpha$-amanitin (9) proved less potent than $\alpha$-amanitin in all cell lines (see Table 3, cf. entry 1 with entries 2-4). In general, one can conclude that the "uncleavable" compounds $\mathbf{7}$ and $\mathbf{8}$ are much less cytotoxic than free $\alpha$-amanitin, while the lysosomally cleavable compounds $\mathbf{9 - 1 1}$ show variable results, with RGD compound 9 behaving worse than the free drug but better than the corresponding uncleavable conjugate 7. The isoDGR motif gives generally better results, with $\mathbf{1 0}$ and $\mathbf{1 1}$ behaving 
Table 3: Evaluation of anti-proliferative activity of $\alpha$-amanitin and $\alpha$-amanitin conjugates 7-11 in U-87, MDA-MB-468 and A549.

\begin{tabular}{|c|c|c|c|c|}
\hline \multirow[t]{2}{*}{ entry } & \multirow[t]{2}{*}{ structure (name) } & \multicolumn{3}{|c|}{$\mathrm{IC}_{50}(\mathrm{nM})^{\mathrm{a}}$} \\
\hline & & U87 $\left(\alpha_{\mathrm{V}} \beta_{3^{+}}\right)$ & MDA-MB-468 $\left(\alpha_{\mathrm{V}} \beta_{3^{-}}\right)$ & $A 549\left(\alpha_{v} \beta_{3^{-}}\right)$ \\
\hline 1 & a-amanitin & $347 \pm 132.5^{b}$ & $185 \pm 49.6^{b}$ & $518 \pm 305^{b}$ \\
\hline 2 & cyclo[DKP-RGD]-uncleavable-a-amanitin (7) & $2552 \pm 37.6$ & $1111 \pm 228.4$ & n.d. ${ }^{\mathrm{C}}$ \\
\hline 3 & cyclo[DKP-isoDGR]-uncleavable-a-amanitin (8) & $3355 \pm 19.1$ & $2200 \pm 96.2$ & n.d. ${ }^{\mathrm{c}}$ \\
\hline 4 & cyclo[DKP-RGD]-Val-Ala-a-amanitin (9) & $1446 \pm 83.9$ & $202 \pm 10.3$ & $2160 \pm 23.3$ \\
\hline 5 & cyclo[DKP-isoDGR]-Val-Ala- $\alpha$-amanitin (10) & $143 \pm 33.8$ & $59 \pm 23.4$ & $217 \pm 98.3$ \\
\hline 6 & cyclo[DKP-isoDGR]-PEG-4-Val-Ala-a-amanitin (11) & $165 \pm 4.0$ & $66 \pm 24.1$ & $720 \pm 98.1$ \\
\hline
\end{tabular}

${ }^{\mathrm{a}} \mathrm{IC}_{50}$ values were calculated as the concentration of compound required for $50 \%$ inhibition of cell viability. All cell lines were treated with different concentrations of $\alpha$-amanitin and compounds $7-11$ for 96 hours. The samples were measured in triplicate. ${ }^{b}$ Average values from three independent experiments. ${ }^{c}$ n.d.: these data could not be determined.

much better than the corresponding uncleavable conjugate $\mathbf{8}$ and slightly better than the free drug. Apparently, for all the $\alpha$-amanitin conjugates there is no direct correlation between the cytotoxicity and the expression of $\alpha_{V} \beta_{3}$ integrin [39].

To determine whether the increased cytotoxicity of cyclo[DKPisoDGR]- $\alpha$-amanitin conjugates $\mathbf{1 0}$ and $\mathbf{1 1}$ is governed by an integrin-mediated binding and internalization process, competition experiments [40] were carried out in which conjugates $\mathbf{1 0}$ and 11 were tested on U87 $\left(\alpha_{V} \beta_{3}+, \alpha_{V} \beta_{5}+, \alpha_{V} \beta_{6}-, \alpha_{5} \beta_{1}+\right)$ [34-36] and on MDA-MB-468 ( $\left.\alpha_{\mathrm{V}} \beta_{3^{-}}, \alpha_{\mathrm{V}} \beta_{5^{+}}, \alpha_{\mathrm{V}} \beta_{6^{+}}, \alpha_{5} \beta_{1^{-}}\right)$ [34-36] cells in the presence of 50-fold excess of cilengitide [23], with the aim of blocking integrins on the cell surface (Table 4, see also Supporting Information File 1, Biological assays). Using the U87 cell line, a modest $\mathrm{IC}_{50}$ increase of conjugate 11 from $91 \mathrm{nM}$ (without cilengitide) to $143 \mathrm{nM}$ (with excess cilengitide) was observed (Table 4 , entry 2). Using the MDA-MB-468 cell line, a more pronounced $\mathrm{IC}_{50}$ increase was observed for both conjugates 10 (from $47 \mathrm{nM}$ without cilengitide to $259 \mathrm{nM}$ with excess cilengitide; Table 4, entry 1) and 11 (from $65 \mathrm{nM}$ without cilengitide to $340 \mathrm{nM}$ with excess cilengitide; Table 4, entry 2). From these results, no correlation emerges between the expression of integrin $\alpha_{V} \beta_{3}$ and cytotoxicity. However, it should be noted that these cell lines overexpress other integrins $\left(\alpha_{5} \beta_{1}\right.$ in U87, $\alpha_{\mathrm{V}} \beta_{6}$ in MDA-MB-468, and $\alpha_{V} \beta_{5}$ in both) [34-36]. Thus, the increase of the $\mathrm{IC}_{50}$ of conjugates $\mathbf{1 0}$ and $\mathbf{1 1}$ (up to 5.5 times) may be possibly due to the block of other integrins with excess cilengitide, which is known to efficiently bind not only $\alpha_{\mathrm{V}} \beta_{3}\left(\mathrm{IC}_{50}=0.6 \mathrm{nM}\right)$ [23], but also $\alpha_{\mathrm{V}} \beta_{5}\left(\mathrm{IC}_{50}=8.4 \mathrm{nM}\right)[23], \alpha_{\mathrm{V}} \beta_{6}\left(\mathrm{IC}_{50}=82.8 \mathrm{nM}\right)$ [41], and $\alpha_{5} \beta_{1}\left(\mathrm{IC}_{50}=14.9 \mathrm{nM}\right)[23]$.

\section{Conclusion}

In this paper, two cyclo[DKP-RGD]- $\alpha$-amanitin and three cyclo[DKP-isoDGR]- $\alpha$-amanitin conjugates were prepared in good yields following a straightforward synthetic route. Conjugates 7-11 retain good binding affinities for the purified $\alpha_{V} \beta_{3}$ receptor, in the same range as the respective free ligands. Cell proliferation assays were performed with three cell lines possessing different levels of integrin expression: human glioblastoma U87 $\left(\alpha_{V} \beta_{3}+\right)$, human lung carcinoma A549 $\left(\alpha_{V} \beta_{3}-\right)$ and breast adenocarcinoma MDA-MB-468 $\left(\alpha_{V} \beta_{3}-\right)$. With all these cell lines the cyclo[DKP-isoDGR]- $\alpha-$ amanitin conjugate $\mathbf{1 0}$ proved slightly more potent than

\begin{tabular}{|c|c|c|c|}
\hline \multirow[t]{2}{*}{ entry } & \multirow[t]{2}{*}{ compound } & \multicolumn{2}{|c|}{$\mathrm{IC}_{50}(\mathrm{nM})^{\mathrm{a}}$} \\
\hline & & U87 ( $\left.\alpha_{v} \beta_{3^{+}}, \alpha_{v} \beta_{5^{+}}, \alpha_{v} \beta_{6^{-}}, \alpha_{5} \beta_{1}+\right)$ & MDA-MB-468 ( $\left.\alpha_{v} \beta_{3^{-}}, \alpha_{v} \beta_{5^{+}}, \alpha_{v} \beta_{6}+, \alpha_{5} \beta_{1}-\right)$ \\
\hline \multirow{2}{*}{1} & 10 & $107 \pm 26.8$ & $47 \pm 21.1$ \\
\hline & $10+50$-fold excess of cilengitide & $106 \pm 11.6$ & $259 \pm 55.2$ \\
\hline \multirow{2}{*}{2} & 11 & $91 \pm 30.6$ & $65 \pm 17.6$ \\
\hline & $11+50$-fold excess of cilengitide & $143 \pm 59.3$ & $340 \pm 210.3$ \\
\hline
\end{tabular}

${ }^{a} C_{50}$ values were calculated as the concentration of compound required for $50 \%$ inhibition of cell viability. Both cell lines were treated with different concentrations of compounds 10 and 11 in the presence of a 50-fold excess of cilengitide during 96 hours. The samples were measured in triplicate. 
$\alpha$-amanitin, whereas conjugate $\mathbf{1 1}$ showed enhanced potency compared to the free drug only on U87 and MDA-MB-468 cells.

Apparently, for all these $\alpha$-amanitin conjugates there is no correlation between the cytotoxicity and the expression of $\alpha_{V} \beta_{3}$ integrin. To determine whether the slightly increased cytotoxicity of cyclo[DKP-isoDGR]- $\alpha$-amanitin conjugates $\mathbf{1 0}$ and $\mathbf{1 1}$ is governed by an integrin-mediated binding and internalization process, competition experiments were carried out in which conjugates 10 and 11 were tested with U87 $\left(\alpha_{V} \beta_{3}+, \alpha_{V} \beta_{5^{+}}\right.$, $\left.\alpha_{V} \beta_{6^{-}}, \alpha_{5} \beta_{1^{+}}\right)$and MDA-MB-468 $\left(\alpha_{V} \beta_{3}-, \alpha_{V} \beta_{5}+, \alpha_{V} \beta_{6^{+}}\right.$, $\alpha_{5} \beta_{1}-$ ) cells in the presence of 50 -fold excess of cilengitide, with the aim of blocking integrins on the cell surface. Using the U87 cell line, a modest increase of the conjugate $\mathbf{1 1} \mathrm{IC}_{50}$ was observed in the presence of cilengitide. Employing the MDAMB-468 cell line, a more pronounced increase of $\mathrm{IC}_{50}$ was observed for both conjugates $\mathbf{1 0}$ and $\mathbf{1 1}$ in the presence of cilengitide. Therefore, it appears that blocking integrins with excess cilengitide, which is known to strongly bind not only $\alpha_{V} \beta_{3}$, but also $\alpha_{V} \beta_{5}, \alpha_{V} \beta_{6}$, and $\alpha_{5} \beta_{1}$, results in an increase (up to 5.5 times) of the $\mathrm{IC}_{50}$ of conjugates $\mathbf{1 0}$ and $\mathbf{1 1}$ with the MDAMB-468 cell line. These data suggest that cyclo[DKP-isoDGR]$\alpha$-amanitin conjugates $\mathbf{1 0}$ and $\mathbf{1 1}$ are possibly internalized by a process mediated by integrins different from $\alpha_{\mathrm{V}} \beta_{3}$ (e.g., $\alpha_{\mathrm{V}} \beta_{5}$ ), though the exact nature of this involvement is not clearly defined [42].

Finally, the $\mathrm{IC}_{50}$ values of the integrin ligand- $\alpha$-amanitin conjugates are much worse (cytotoxicity increased three times compared to $\alpha$-amanitin) than those exhibited by antibody $\alpha$-amanitin conjugates for which the increase of cytotoxicity is 100-100000 times [5]. Therefore, despite the remarkable progresses that have been realized in recent years, integrin targeting SMDCs are still far from the clinic.

\section{Experimental}

Functionalized ligands $\mathrm{H}_{2} \mathrm{NCH}_{2}$-cyclo[DKP-RGD] (2) and $\mathrm{H}_{2} \mathrm{NCH}_{2}$-cyclo[DKP-isoDGR] (4) were prepared according to the literature [28,29]. 6 '-Functionalized $\alpha$-amanitin derivatives 12a and 12b were prepared according to references $[43,44]$.

\section{Supporting Information}

\section{Supporting Information File 1}

Experimental details, characterization data and copies of spectra.

[https://www.beilstein-journals.org/bjoc/content/ supplementary/1860-5397-14-29-S1.pdf]

\section{Acknowledgements}

We thank the European Commission (Marie Skłodowska-Curie ITN MAGICBULLET 642004) for PhD fellowships (to L.B., P.L.R., B.K.) and financial support.

\section{ORCID ${ }^{\circledR} \mathrm{iDs}$}

Lizeth Bodero - https://orcid.org/0000-0003-2552-0064

Paula López Rivas - https://orcid.org/0000-0002-0539-8682

Daniela Arosio - https://orcid.org/0000-0001-5486-3504 Luca Pignataro - https://orcid.org/0000-0002-7200-9720

Cesare Gennari - https://orcid.org/0000-0002-7635-4900

Umberto Piarulli - https://orcid.org/0000-0002-6952-1811

\section{References}

1. Wieland, T.; Faulstich, H. Experientia 1991, 47, 1186-1193. doi:10.1007/BF01918382

2. Anderl, J.; Echner, H.; Faulstich, H. Beilstein J. Org. Chem. 2012, 8, 2072-2084. doi:10.3762/bjoc.8.233

3. Letschert, K.; Faulstich, H.; Keller, D.; Keppler, D. Toxicol. Sci. 2006, 91, 140-149. doi:10.1093/toxsci/kfj141

4. Davis, M. T.; Preston, J. F., III. Science 1981, 213, 1385-1388. doi:10.1126/science.6115471

5. Moldenhauer, G.; Salnikov, A. V.; Lüttgau, S.; Herr, I.; Anderl, J.; Faulstich, H. J. Natl. Cancer Inst. 2012, 104, 622-634. doi:10.1093/jnci/djs140

6. Krall, N.; Scheuermann, J.; Neri, D. Angew. Chem., Int. Ed. 2013, 52 1384-1402. doi:10.1002/anie.201204631

7. Moshnikova, A.; Moshnikova, V.; Andreev, O. A.; Reshetnyak, Y. K. Biochemistry 2013, 52, 1171-1178. doi:10.1021/bi301647y

8. Zhao, L.; May, J. P.; Blanc, A.; Dietrich, D. J.; Loonchanta, A.; Matinkhoo, K.; Pryyma, A.; Perrin, D. M. ChemBioChem 2015, 16, 1420-1425. doi:10.1002/cbic.201500226

9. Desgrosellier, J. S.; Cheresh, D. A. Nat. Rev. Cancer 2010, 10, 9-22. doi:10.1038/nrc2748

10. Danhier, F.; Le Breton, A.; Préat, V. Mol. Pharmaceutics 2012, 9 2961-2973. doi:10.1021/mp3002733

11. De Franceschi, N.; Hamidi, H.; Alanko, J.; Sahgal, P.; Ivaska, J. J. Cell Sci. 2015, 128, 839-852. doi:10.1242/jcs.161653

12. Pierschbacher, M. D.; Ruoslahti, E. Nature 1984, 309, 30-33. doi:10.1038/309030a0

13. Biochemical studies have shown that a spontaneous post-translational modification, occurring at the Asn-Gly-Arg (NGR) motif of the extracellular matrix protein fibronectin, leads to the isoAspGlyArg (isoDGR) sequence.

14. Curnis, F.; Longhi, R.; Crippa, L.; Cattaneo, A.; Dondossola, E.; Bachi, A.; Corti, A. J. Biol. Chem. 2006, 281, 36466-36476. doi:10.1074/jbc.M604812200

15. Curnis, F.; Sacchi, A.; Gasparri, A.; Longhi, R.; Bachi, A.; Doglioni, C.; Bordignon, C.; Traversari, C.; Rizzardi, G.-P.; Corti, A. Cancer Res. 2008, 68, 7073-7082. doi:10.1158/0008-5472.CAN-08-1272

16. Corti, A.; Curnis, F. J. Cell Sci. 2011, 124, 515-522. doi: $10.1242 / j \mathrm{jcs} .077172$

17. Biochemical, spectroscopic and computational investigations showed that the isoDGR sequence can fit into the RGD-binding pocket of $\alpha_{\mathrm{v}} \beta_{3}$ integrin, establishing the same electrostatic clamp as well as additional polar interactions, see ref. [18-20]. 
18. Spitaleri, A.; Mari, S.; Curnis, F.; Traversari, C.; Longhi, R.; Bordignon, C.; Corti, A.; Rizzardi, G.-P.; Musco, G. J. Biol. Chem. 2008, 283, 19757-19768. doi:10.1074/jbc.M710273200

19. Curnis, F.; Cattaneo, A.; Longhi, R.; Sacchi, A.; Gasparri, A. M.; Pastorino, F.; Di Matteo, P.; Traversari, C.; Bachi, A.; Ponzoni, M.; Rizzardi, G.-P.; Corti, A. J. Biol. Chem. 2010, 285, 9114-9123. doi:10.1074/jbc.M109.044297

20. Ghitti, M.; Spitaleri, A.; Valentinis, B.; Mari, S.; Asperti, C.; Traversari, C.; Rizzardi, G.-P.; Musco, G. Angew. Chem., Int. Ed. 2012 51, 7702-7705. doi:10.1002/anie.201202032

21. Gottschalk, K.-E.; Kessler, H. Angew. Chem., Int. Ed. 2002, 41, 3767-3774. doi:10.1002/1521-3773(20021018)41:20<3767::AID-ANIE3767>3.0.CO ;2-T

22. Auzzas, L.; Zanardi, F.; Battistini, L.; Burreddu, P.; Carta, P.; Rassu, G.; Curti, C.; Casiraghi, G. Curr. Med. Chem. 2010, 17, 1255-1299. doi:10.2174/092986710790936301

23. Kapp, T. G.; Rechenmacher, F.; Neubauer, S.; Maltsev, O. V.; Cavalcanti-Adam, E. A.; Zarka, R.; Reuning, U.; Notni, J.; Wester, H.-J.; Mas-Moruno, C.; Spatz, J.; Geiger, B.; Kessler, H. Sci. Rep. 2017, 7, No. 39805. doi:10.1038/srep39805

24. da Ressurreição, A. S. M.; Vidu, A.; Civera, M.; Belvisi, L.; Potenza, D.; Manzoni, L.; Ongeri, S.; Gennari, C.; Piarulli, U. Chem. - Eur. J. 2009, 15, 12184-12188. doi:10.1002/chem.200902398

25. Marchini, M.; Mingozzi, M.; Colombo, R.; Guzzetti, I.; Belvisi, L.; Vasile, F.; Potenza, D.; Piarulli, U.; Arosio, D.; Gennari, C. Chem. - Eur. J. 2012, 18, 6195-6207. doi:10.1002/chem.201200457

26. Mingozzi, M.; Dal Corso, A.; Marchini, M.; Guzzetti, I.; Civera, M.; Piarulli, U.; Arosio, D.; Belvisi, L.; Potenza, D.; Pignataro, L.; Gennari, C. Chem. - Eur. J. 2013, 19, 3563-3567. doi:10.1002/chem.201204639

27. Panzeri, S.; Zanella, S.; Arosio, D.; Vahdati, L.; Dal Corso, A.; Pignataro, L.; Paolillo, M.; Schinelli, S.; Belvisi, L.; Gennari, C.; Piarulli, U. Chem. - Eur. J. 2015, 21, 6265-6271. doi:10.1002/chem.201406567

28. Colombo, R.; Mingozzi, M.; Belvisi, L.; Arosio, D.; Piarulli, U.; Carenini, N.; Perego, P.; Zaffaroni, N.; De Cesare, M.; Castiglioni, V.; Scanziani, E.; Gennari, C. J. Med. Chem. 2012, 55, 10460-10474. doi:10.1021/jm301058f

29. Dal Corso, A.; Caruso, M.; Belvisi, L.; Arosio, D.; Piarulli, U.; Albanese, C.; Gasparri, F.; Marsiglio, A.; Sola, F.; Troiani, S.; Valsasina, B.; Pignataro, L.; Donati, D.; Gennari, C. Chem. - Eur. J. 2015, 21, 6921-6929. doi:10.1002/chem.201500158

30. Zanella, S.; Angerani, S.; Pina, A.; López Rivas, P.; Giannini, C.; Panzeri, S.; Arosio, D.; Caruso, M.; Gasparri, F.; Fraietta, I.; Albanese, C.; Marsiglio, A.; Pignataro, L.; Belvisi, L.; Piarulli, U.; Gennari, C. Chem. - Eur. J. 2017, 23, 7910-7914. doi:10.1002/chem.201701844

31. Dal Corso, A.; Pignataro, L.; Belvisi, L.; Gennari, C. Curr. Top. Med. Chem. 2016, 16, 314-329. doi:10.2174/1568026615666150701114343

32. Kwon, K. C.; Ko, H. K.; Lee, J.; Lee, E. J.; Kim, K.; Lee, J. Small 2016, 12, 4241-4253. doi:10.1002/smll.201600917

33. Goodman, S. L.; Grote, H. J.; Wilm, C. Biol. Open 2012, 1, 329-340. doi:10.1242/bio.2012364

34. Bai, S. Y.; Xu, N.; Chen, C.; Song, Y.-I.; Hu, J.; Bai, C.-X. Clin. Respir. J. 2015, 9, 457-467. doi:10.1111/crj.12163
35. Currier, N. V.; Ackerman, S. E.; Kintzing, J. R.; Chen, R.; Interrante, M. F.; Steiner, A.; Sato, A. K.; Cochran, J. R. Mol. Cancer Ther. 2016, 15, 1291-1300. doi:10.1158/1535-7163.MCT-15-0881

36. Meyer, T.; Marshall J. F.; Hart, I. R. Br. J. Cancer 1998, 77, 530-536. doi:10.1038/bjc.1998.86 For reports on the lack of $\beta 3$ integrin expression in MDA-MB-468, see also ref. [32,33].

37. Liu, Z.; Yan, Y.; Liu, S.; Wang, F.; Chen, X. Bioconjugate Chem. 2009, 20, 1016-1025, and ref. [38]. doi:10.1021/bc9000245

38. Lautenschlaeger, T.; Perry, J.; Peereboom, D.; Li, B.; Ibrahim, A.; Huebner, A.; Meng, W.; White, J.; Chakravarti, A. Radiat. Oncol. 2013, 8, No. 246. doi:10.1186/1748-717X-8-246

39. Sancey, L.; Garanger, E.; Foillard, S.; Schoehn, G.; Hurbin, A.; Albiges-Rizo, C.; Boturyn, D.; Souchier, C.; Grichine, A.; Dumy, P.; Coll, J.-L. Mol. Ther. 2009, 17, 837-843. doi:10.1038/mt.2009.29

40. Cox, N.; Kintzing, J. R.; Smith, M.; Grant, G. A.; Cochran, J. R. Angew. Chem., Int. Ed. 2016, 55, 9894-9897. doi:10.1002/anie.201603488 Angew. Chem. 2016, 128, 10048-10051. doi:10.1002/ange.201603488

41. Civera, M.; Arosio, D.; Bonato, F.; Manzoni, L.; Pignataro, L.; Zanella, S.; Gennari, C.; Piarulli, U.; Belvisi, L. Cancers 2017, 9, No. 128. doi:10.3390/cancers 9100128

42. Memmo, L. M.; McKeown-Longo, P. J. Cell Sci. 1998, 111, 425-433.

43. Anderl, J.; Mueller, C.; Simon, W. Amatoxin-conjugates with improved linkers. WO Patent WO2012041504, April 5, 2012.

44. Anderl, J.; Hechler, T.; Mueller, C.; Pahl, A. Amatoxin-antibody conjugates. WO Patent WO 2016142049, Sept 15, 2016.

\section{License and Terms}

This is an Open Access article under the terms of the Creative Commons Attribution License (http://creativecommons.org/licenses/by/4.0), which permits unrestricted use, distribution, and reproduction in any medium, provided the original work is properly cited.

The license is subject to the Beilstein Journal of Organic Chemistry terms and conditions: (https://www.beilstein-journals.org/bjoc)

The definitive version of this article is the electronic one which can be found at: $\underline{\text { doi: } 10.3762 / \text { bjoc. } 14.29}$ 